University of Nebraska - Lincoln

DigitalCommons@University of Nebraska - Lincoln

$2-2008$

\title{
Herbivore-Mediated Ecological Costs of Reproduction Shape the Life History of an Iteroparous Plant
}

Tom E. X. Miller

University of Nebraska - Lincoln

Brigitte Tenhumberg

University of Nebraska - Lincoln, btenhumberg2@unl.edu

Svata M. Louda

University of Nebraska - Lincoln, slouda1@unl.edu

Follow this and additional works at: https://digitalcommons.unl.edu/bioscifacpub

Part of the Life Sciences Commons

Miller, Tom E. X.; Tenhumberg, Brigitte; and Louda, Svata M., "Herbivore-Mediated Ecological Costs of Reproduction Shape the Life History of an Iteroparous Plant" (2008). Faculty Publications in the Biological Sciences. 54.

https://digitalcommons.unl.edu/bioscifacpub/54

This Article is brought to you for free and open access by the Papers in the Biological Sciences at DigitalCommons@University of Nebraska - Lincoln. It has been accepted for inclusion in Faculty Publications in the Biological Sciences by an authorized administrator of DigitalCommons@University of Nebraska - Lincoln. 


\title{
Herbivore-Mediated Ecological Costs of Reproduction Shape the Life History of an Iteroparous Plant
}

\author{
Tom E. X. Miller, ${ }^{1, *}$ Brigitte Tenhumberg, ${ }^{1,2, \dagger}$ and Svata M. Louda ${ }^{1, \neq}$
}

1. School of Biological Sciences, University of Nebraska, Lincoln, Nebraska 68588;

2. Department of Mathematics, University of Nebraska, Lincoln, Nebraska 68588

Submitted June 29, 2007; Accepted September 11, 2007; Electronically published December 5, 2007

Online enhancements: appendix, figures.
Keywords: cost of reproduction, dynamic programming, herbivory, life-history evolution, Opuntia, resource allocation.

Organisms face decisions regarding when (at what size, stage, or age) to reproduce and how much (what fraction of available resources) to invest in each reproductive event. Reproductive strategies are highly variable within and among species and fall along a continuum from semelparity (single, fatal reproductive event) to iteroparity (multiple bouts of reproduction distributed across a lifetime). Understanding the processes that shape reproductive strategies is a central goal in the study of life histories. Theory posits that because reproduction can be costly, natural selection should favor life histories that distribute the benefits and costs of reproduction across a lifetime such that fitness is maximized (Partridge and Harvey 1988; Partridge et al. 1991; Stearns 1992; Roff 2002). Identifying the costs of reproduction is therefore critical to our understanding of life-history evolution.

There is a large body of empirical and theoretical work examining the costs of reproduction in plants (Harper 1977; Bazzaz and Grace 1997; Primack and Stacey 1998; Ehrlen and van Groenendael 2001; Obeso 2002; Reekie and Bazzaz 2005). Nearly all of these studies focus on the direct, physiological costs of reproduction that arise from allocation constraints or the inability to simultaneously maximize all life-history functions. Resources allocated to vegetative functions (growth/storage) make little or no contribution to current reproductive output but contribute to future fitness gains via positive effects on size, probability of survival, and future fecundity. Conversely, resources allocated to current reproduction can yield immediate fitness benefits (seeds) but often at the expense of growth, survival, and future fecundity. Thus, direct costs of reproduction are driven by trade-offs between current reproductive output and future reproductive potential.

In addition to direct costs, plant reproduction may also incur indirect ecological costs. Ecological costs arise from a change in the frequency of interactions with antagonists or mutualists in a way that reduces fitness. These are distinct from direct costs in that ecological costs are mani0003-0147/2008/17102-42702\$15.00. All rights reserved. DOI: $10.1086 / 524961$ 
fested only in the presence of additional interacting species (Strauss et al. 2002). In plants, ecological costs have received most attention in the context of antiherbivore defense. For example, plant traits that deter herbivores can also deter mutualists (Strauss et al. 1999; Agrawal et al. 2002; Ness 2006), and defenses against particular enemies can increase susceptibility to others (Da Costa and Jones 1971; Agrawal et al. 1999). This work suggests that ecological costs may influence trait evolution by constraining responses to selection and shifting phenotypic optima (e.g., maximally defended plants may not have maximum fitness). Similarly, plant reproduction may also incur ecological costs if it increases apparency to herbivores (Courtney 1985; Prins et al. 1992) or if herbivore abundance and population growth are positively affected by host plant reproductive effort (Miller et al. 2006; Miller 2007a). Such dynamic responses by herbivores to plant allocation could weaken the fitness returns on reproductive investment and play a role in the evolution of plant life-history strategies. Indeed, the significance of ecological reproductive costs has long been recognized in animal behavioral ecology, where it has been shown that courtship behaviors and displays can increase susceptibility to predators (Calow 1979; Tuttle and Ryan 1981; Partridge and Harvey 1988). In contrast, ecological costs of reproduction in plants have received little attention (Klinkhamer et al. 1997; Rose et al. 2005) and remain poorly integrated into plant lifehistory theory (Obeso 2002).

Our research focused on the tree cholla (Opuntia imbricata), a long-lived ( $>20$ year) iteroparous cactus in the Chihuahuan Desert of central New Mexico. Early in each growing season, undifferentiated meristems appear on the terminal ends of cactus branches, and the plant must then "decide" the fate of each (fig. 1). Meristems allocated to vegetative growth develop into cylindrical segments, elongate over the growing season, and contribute to plant size in subsequent years. Meristems allocated to reproduction develop into flower buds, and those that do not abort eventually flower, set seed, and disperse as ripe fruits at the end of the growing season. Prior work suggests that tree cholla reproductive effort $(R)$ - the proportion of available meristems that are allocated to reproductionpositively influences the population dynamics of the cactus bug (Narnia pallidicornis; Miller et al. 2006; Miller 2007a), a specialist herbivore.

We conducted field experiments to test the hypothesis that tree cholla cacti incur indirect ecological costs of reproduction, mediated by the cactus bug. We then developed theory, motivated by the experimental data, to examine whether and how ecological costs influence plant life-history strategies. Our results suggest that dynamic responses by herbivores to plant reproductive allocation can play an important role in shaping plant life histories.

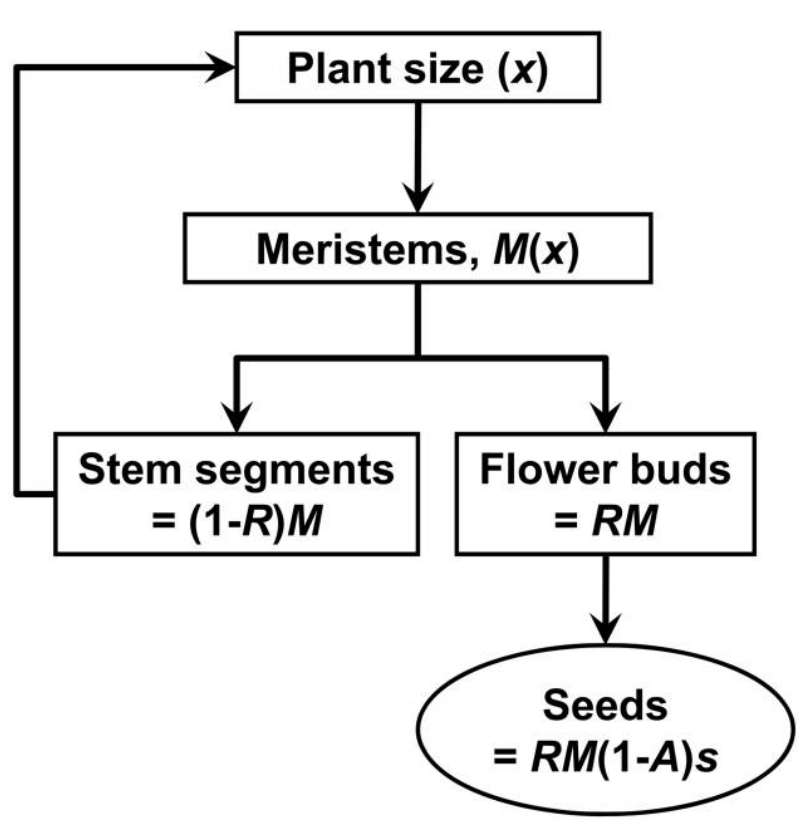

Figure 1: Dynamics of meristem allocation by tree cholla cacti. The number of meristems $(M)$ produced in each year is dependent on plant size, in stem segments $(x)$. Reproductive effort $(R)$ is the proportion of meristems allocated to reproduction. The total number of seeds produced by a plant in a given year is determined by the number of meristems that form flower buds $(R M)$, the proportion of flower buds that do not abort $(1-A)$, and the number of seeds per fruit $(s)$. Meristems allocated to stem segments $([1-R] M)$ contribute to plant growth and subsequent size.

\section{Material and Methods}

\section{Natural History of Empirical System}

The tree cholla cactus (Opuntia imbricata [Haw.] D.C.) occurs throughout the Chihuahuan Desert and arid grassland habitats of the southwest United States (Benson 1982). Tree cholla initiate meristems in early spring. Flowering occurs in June, and the flowers are pollinated by bees and beetles (McFarland et al. 1989). Unlike other Opuntia cacti, tree cholla at our study sites does not regenerate from detached stem segments (Miller 2007c), and so we focus on seeds as the sole fitness currency.

Throughout its range, tree cholla is attacked by the cactus bug (Narnia pallidicornis Stål [Hemiptera: Coreidae]), a phloem-feeding insect that specializes on Opuntia cacti (Mann 1969). There are two overlapping generations per year in central New Mexico, and juveniles and adults cooccur throughout the growing season (Miller et al. 2006). Adults overwinter among debris near the base of the plant, and females deposit eggs on cactus spines in late spring. 
The first cohort of nymphs reaches maturity in June, and the second cohort matures in September. Adults are reluctant but capable fliers and can move among neighboring plants, while juveniles are flightless and generally complete their development on a single plant (A. Benhumea and T. E. X. Miller, unpublished data). Cactus bugs can feed on all cactus parts but show a preference for reproductive structures (Mann 1969). While a number of other specialist insects also feed on tree cholla (Miller 2007b, $2007 c$ ), cactus bugs are the most abundant herbivores during the period of floral development and are the only herbivores that use the developing flower buds (T. E. X. Miller, personal observations). Tree cholla and cactus bugs both commonly occur at the Sevilleta National Wildlife Refuge (NWR), a long-term ecological research site in central New Mexico (http://sev.lternet.edu/), where the field component of this research was conducted.

\section{Gibberellic Acid Experiment}

First, we experimentally manipulated tree cholla meristem allocation to test the hypothesis that increasing $R$ leads to increased attack by the cactus bug. In early spring 2006, as meristems were becoming externally visible but before any differentiation had occurred, we selected 60 mature tree cholla in each of two spatial blocks $(N=120)$. On April 15, 100\%, 50\%, or $0 \%$ of meristems on each plant were injected with $0.5 \mathrm{~mL}$ of gibberellic acid $\left(\mathrm{GA} ; 10^{-4} \mathrm{M}\right.$ $\mathrm{GA}_{3}$; Fisher Scientific), according to random treatment assignments. The mean (SEM) number of meristems per plant was 66.23 (3.18) meristems. GA, a natural plant hormone, is a mitotic stimulant and inhibits the transition of cactus meristems from vegetative elongation to floral development (Pimienta-Barrios and del Castillo 2002). For the $50 \%$ treatment, the meristems injected with GA were chosen randomly within a plant. For plants in the $0 \%$ GA (control) treatment, all stem segments and flower buds were injected with GA in late May, once meristem differentiation was complete. This treatment was intended to control for any unintended effects of GA on plant performance or herbivore abundance. We recorded the value of $R$ for experimental plants on May 18-19 and counted the numbers of cactus bugs on each plant on May 18-19, June 14-15, August 15-16, and September 9-10. We compared reproductive effort and cumulative cactus bug abundance among GA treatments using ANOVA with treatment and block as fixed and random effects, respectively. We also used simple linear regression to analyze bug abundance in relation to $R$ for individual sampling dates (see "State Dynamic Programming Model of Meristem Allocation").

\section{Herbivore Exclusion Experiment}

Second, to evaluate the impacts of herbivory by cactus bugs on components of plant fitness, we applied insecticide to tree cholla over four consecutive growing seasons (2003-2006). This experiment included 30 mature tree cholla in each of three spatial blocks at the Sevilleta NWR $(N=90)$. Blocks were separated by $\sim 1 \mathrm{~km}$. Within each block, plants were randomly assigned to insecticide, water control, or dry control treatments. Plants assigned to the insecticide treatment were sprayed with carbaryl, a nonsystemic carbamate insecticide ( $0.9 \mathrm{fl} \mathrm{oz}$ active ingredient/ gal $\mathrm{H}_{2} \mathrm{O}$ ). In a greenhouse experiment, carbaryl had no direct effect on plant growth rate $(t=0.86, \mathrm{df}=18$, $P=.4$; see also Miller 2007c). The water control treatment consisted of equal, similarly applied amounts of water, and dry control plants were unmanipulated. These treatments were applied to all plants every 2 weeks from early May to early September of 2004, 2005, and 2006. In addition, 30 plants in one spatial block also received these treatments every 2 weeks during the 2003 growing season. We quantified cactus bug abundance and tree cholla flower bud abortions in the spring of each year (2003: June 2-4; 2004: May 24-27; 2005: May 27-31; 2006: May 21-24). We focused our analyses on these early-season data to isolate the impacts of cactus bugs from those of the rest of the cactus insect community, which emerges later in the season (T. E. X. Miller, unpublished data). We used repeatedmeasures ANOVA to examine the effects of treatment, year, and treatment $x$ year interaction on insect abundance (square root transformed) and the proportion of floral buds aborted (arcsine-square root transformed). The statistical model included block as a random effect, an autoregressive error structure, and individual plants as the units of repeated observation. Statistical analyses were conducted using SAS, version 8.2.

\section{State Dynamic Programming Model of Meristem Allocation}

Next, we asked whether the herbivore-mediated costs of reproduction that we found in the field experiments (see "Results") could alter the optimal life-history strategy (the distribution of reproduction that maximizes lifetime fitness), relative to expectations based solely on direct costs. To answer this question, we developed a state dynamic programming (SDP) model of meristem allocation. The key feature of SDP models is their ability to identify optimal decisions, in the face of trade-offs, based on an organism's state (Clark and Mangel 2000; Tenhumberg et al. 2001, 2006). The model steps backward through time from the final time horizon $(T)$, tallies the current and future 
fitness consequences of all possible decisions, and identifies the decision that maximizes fitness.

Our model is based on the dynamics of cactus meristem allocation, growth, and reproduction, shown in figure 1. The decision variable of interest is $R$, and the corresponding dynamic programming algorithm is

$$
\begin{aligned}
& F(x, t)=\max _{0 \leq R \leq 1}(\mu\{R M(1-A) s \\
& +F[x+(1-R) M, t+1]\}),
\end{aligned}
$$

where $x$ (the state variable) is size in stem segments, $t$ is time in years, $\mu$ is the probability of survival, $M$ is the number of available meristems, $A$ is the proportion of flower buds aborted before flowering, and $s$ is the number of seeds per fruit. Fitness $(F)$ consists of current seed output $(R M[1-A] s)$ plus expected fitness at next year's size, determined by the growth increment $([1-R] M)$. With the initial condition that fitness at the time of death $(T)$ is 0 , this algorithm identifies, for each time-state combination, the value of $R$ that maximizes lifetime reproductive success (and would therefore be favored by natural selection). We found that the optimal decisions were independent of time shortly after the initial condition $(F(x, T)=0)$ regardless of the absolute life span ( $T)$, and so we focus strictly on size-dependent reproductive effort. We parameterized the model with empirical data and generated predictions for the optimal value of $R$ at each plant size $(x)$. While we built the model with a particular empirical system in mind, we think that its relatively simple structure offers potential for broad applicability.

We first generated predictions including direct costs of reproduction but ignoring any herbivore-mediated ecological costs. The basic model structure (fig. 1) includes direct costs in the form of size-dependent meristem production. Because allocation of individual meristems to flowering and growth are exclusive alternatives, reproduction involves trade-offs with future size, meristem availability, and potential reproductive output. To estimate size-dependent meristem production, $M(x)$, we collected demographic data from 206 tree cholla at the Sevilleta NWR in 2004 and 2005. We estimated plant size (in stem segments) by measuring plant height and crown width in each year, converting these data to volume of a cone $\left(\mathrm{m}^{3}\right)$, and dividing the change in volume from 2004 to 2005 $\left(\Delta m^{3}\right)$ by the number of stem segments produced in 2004 . The resulting value, averaged across plants, estimated the volume increment associated with each segment, and we used this value to convert volume measurements for each plant to numbers of segments $(x)$. We used the 2005 relationship between size $(x)$ and meristem production to estimate $M(x) \quad(M=4.86+0.382 x, F=577.29$, df $=$ $\left.1,204, P<.0001, R^{2}=0.74\right)$. Because the model is min- imally sensitive to changes in this relationship (see fig. A1 in the online edition of the American Naturalist), the results were qualitatively identical whether we used the 2004 or the 2005 data.

We set the parameter $s$ to 157 seeds per fruit (Miller $2007 b$ ) and, in modeling direct costs only, we set the constant floral abortion rate $(A)$ to 0.32 (mean of control treatments from 2003 to 2006). Model predictions were insensitive to values for $s$ and $A$. We have no evidence for negative effects of reproduction on cactus survival (in fact, we observed zero mortality in our experimental population over 4 years), and so we set survival $(\mu)$ to a constant value (0.99). Model predictions were not sensitive to variation in $\mu$ until very low survival probabilities $(<0.5)$, at which point the optimal strategy was to reproduce maximally $(R=1.0)$ across all sizes. To incorporate ecological costs, we modified the "direct costs only" model so that herbivore damage was responsive to plant reproductive allocation (see "Influence of Ecological Costs of Reproduction on Plant Life-History Strategies").

Our model, implemented in $\mathrm{C}++$, makes the simplifying assumptions that all stem segments are uniformly sized, that seed production is not pollen limited, and that aborted flower buds make zero contribution to fitness. We maximized the SDP model for both net reproductive rate $\left(R_{0}\right)$ and population growth rate $(r)$. We found that the results were qualitatively identical, and so we present results of the simpler $R_{0}$ maximization.

We compared model predictions with independent data on tree cholla size-dependent reproductive effort. These data included 180 plants, representing the population size structure (i.e., a range from very small to very large individuals), which were monitored from 2004 to 2006, and an additional 43 plants monitored from 2003 to 2006 . We pooled all plants and years (trends were consistent across years) and, to better visualize the distribution, we present box plots of discretized data at 50-segment intervals.

\section{Results \\ Evidence for Ecological Costs of Reproduction}

Results from two field experiments in central New Mexico provide strong support for the hypothesis that reproduction by tree cholla cacti incurs herbivore-mediated ecological costs. First, we generated an experimental gradient of host plant $R$. Treatment with GA was effective in reducing reproductive effort (fig. $2 A ; F=4.91$, df $=$ 2, 112, $P=.009$ ), and cactus bug abundance showed a strong response to the variation in $R$ (fig. $2 A ; F=4.09$, $\mathrm{df}=2,112, P=.019)$. Attack by cactus bugs was positively, causally related to host plant reproductive allocation. 

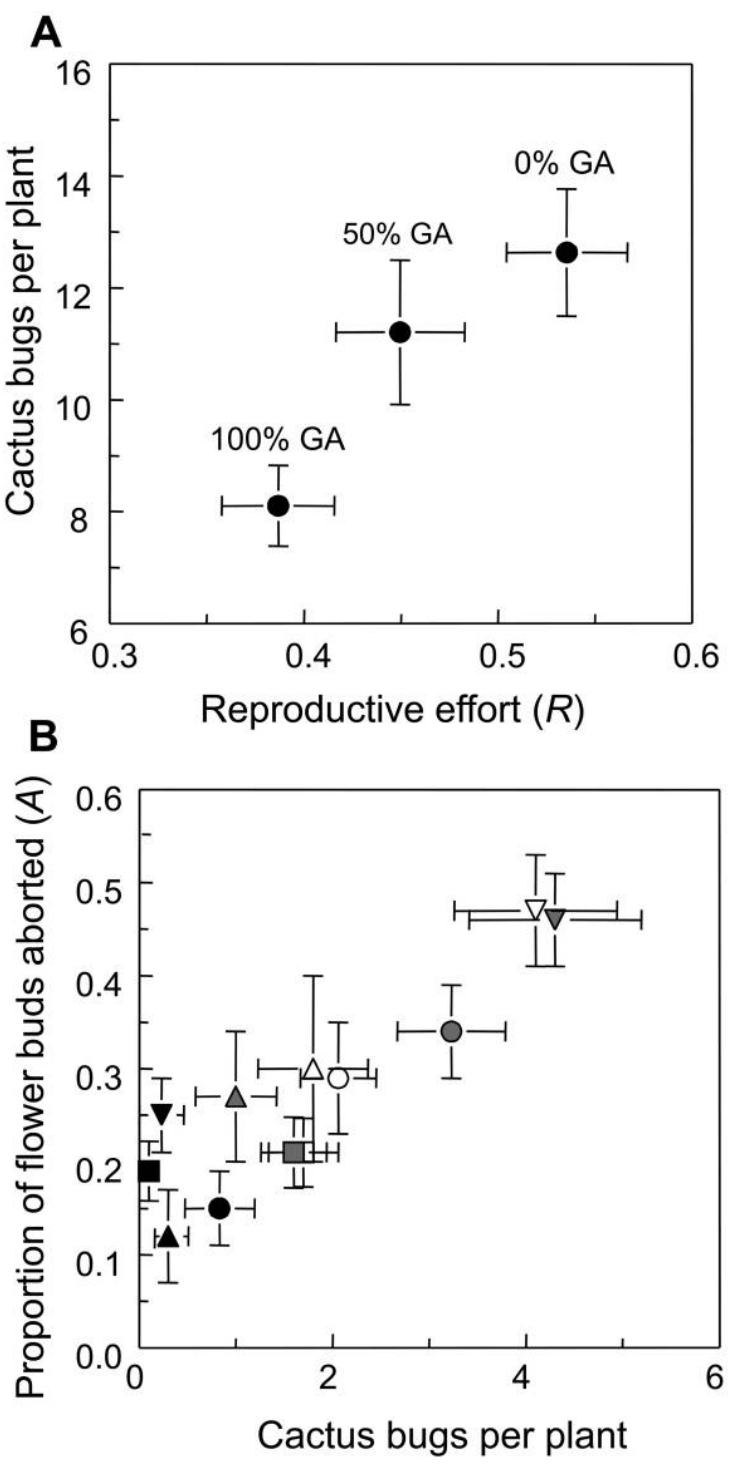

Figure 2: Evidence for ecological costs of plant reproduction. $A, \mathrm{Cu}-$ mulative cactus bug abundance (May-September) in response to experimentally generated variation in tree cholla reproductive effort $(R$, the proportion of meristems allocated to reproduction). Treatments (shown above circles) indicate the proportion of undifferentiated meristems injected with gibberellic acid. $B$, Flower bud abortion by host plants in relation to cactus bug abundance during the period of flower bud development (May-June). Each symbol represents a different year of the experiment (triangle $=2003$, square $=2004$, circle $=2005$, and inverted triangle $=2006)$. Within years, treatment groups are differentiated: black $=$ insecticide, gray $=$ water control, and white $=$ dry control. Points and bars represent means and standard errors of the mean.

Second, we evaluated the impacts of herbivory by cactus bugs on components of plant fitness. In each year of the experiment (2003-2006), cactus bug abundance was significantly lower on insecticide-treated plants than on con- trol plants, which were either unmanipulated or sprayed instead with water (fig. $2 B$; treatment: $F=35.67$, df $=$ 2,283, $P<.0001$; year: $F=1.59, \mathrm{df}=3,284, P=.19$; treatment $\times$ year: $F=1.96, \mathrm{df}=6,283, P=.07)$. The reduction in bug abundance led to a significant reduction in the proportion of initiated flower buds that were aborted before flowering (fig. $2 B$; treatment: $F=8.95$, $\mathrm{df}=2,282, P=.0002$; year: $F=10.73, \mathrm{df}=3,283$, $P<.0001 ;$ treatment $\times$ year: $F=1.25, \quad \mathrm{df}=6,282$, $P=.28$ ). Both within and across years, floral abortion increased as the abundance of cactus bugs increased on experimental plants during the period of flower bud development. Plants in the water control and dry control treatments did not differ in herbivore abundance or floral abortion (results of preplanned contrasts not shown). Thus, the two field experiments indicate that tree cholla reproductive effort led to significant ecological costs: allocation to reproduction increased attack by specialist herbivores, and damage by these insects reduced flowering success, a key component of plant fitness.

\section{Influence of Ecological Costs of Reproduction on Plant Life-History Strategies}

To incorporate ecological costs of reproduction into the SDP model, we used data from the GA experiment to describe the effect of $R$ on early-season bug abundance $\quad$ (bugs $=2.46+6.64 R ; \quad F=9.19, \quad \mathrm{df}=1,116$, $\left.P=.003 ; R^{2}=0.074\right)$, and we used data from the insecticide experiment to describe the effect of cactus bug abundance on the flower bud abortion rate $(A=0.18+$ $0.076 \times$ bugs; intercept $=$ abortion rate of control plants, averaged across years; slope $=$ difference in abortion between control and insecticide plants divided by difference in bug abundance, averaged across years). We used earlyseason data (May and June) from the GA experiment because insects that occur after the period of flower bud development can have no effect on the abortion rate. To simplify sensitivity analyses, we combined these relationships into a single function that links the flower bud abortion rate to reproductive effort $(A=0.36+0.51 R$; herbivores are implicit in this relationship). This function represented our empirical estimate of the ecological cost of reproduction by tree cholla. Under direct costs only, the slope of this relationship was 0 (i.e., the abortion rate was constant). To generalize our model to other iteroparous plants with specialist enemies and to evaluate model sensitivity to uncertainty in parameter estimates, we also generated predictions under "weak" and "strong" ecological costs $(50 \%$ decrease and increase in the slope of the $A-R$ relationship [predictions were insensitive to the in- 
tercept value]) and alternative functional forms (concave, convex). These input functions that determine the strength and shape of ecological costs are shown in the insets of figure 3.

We found that herbivore-mediated ecological costs of reproduction strongly influenced the optimal plant lifehistory strategy. Including ecological costs in the model shifted the optimal strategy toward initiating reproduction at a smaller size and increasing reproductive effort more gradually with size, compared with predictions based solely on direct costs of reproduction (fig. 3). Figure $3 A$ shows predictions based on direct costs only, and figure $3 C$ shows predictions based on both direct costs and our empirical estimate of ecological costs. We also generated predictions for optimal $R$ when ecological costs were $50 \%$ weaker (fig. $3 B$ ) and $50 \%$ stronger (fig. $3 D$ ) than our empirical estimates. This sensitivity analysis showed that more severe ecological costs (stronger responses by herbivores to plant reproduction and/or stronger fitness impacts of herbivory) favored the onset of reproduction at smaller sizes and lower reproductive effort at larger sizes. In addition, differences in optimality predictions with versus without ecological costs were also apparent using alternative functional forms of the floral abortion—reproductive effort relation- ship (fig. $3 E, 3 F$ ). However, in the nonlinear models, the severity of ecological costs varied across plant sizes, and so their predictions were most similar to the direct costs model over the size intervals where the $A-R$ relationship was flattest. Fitness surfaces for the life-history strategies shown in figure 3 are given in figure A2 in the online edition of the American Naturalist. These surfaces describe the fitness consequences of deviations from the optimal allocation strategy.

The clear contrast in optimality predictions with versus without herbivore-mediated costs provided competing expectations for what we should find in nature if, in fact, ecological costs influence plant reproductive strategies or if these strategies are driven solely by direct costs. We tested these alternatives using empirical estimates of tree cholla size-dependent $R$ that were independent of the data used to parameterize the model. We found that plants in the field initiated reproduction at small sizes $(\sim 50 \mathrm{stem}$ segments) and showed a gradual increase in $R$ with size (fig. 4). Even very large plants ( $>400$ stem segments), on average, did not allocate more than $65 \%$ of their meristems to flower buds. The empirical pattern qualitatively matched the reproductive strategy expected under both direct and ecological costs of reproduction on the basis of
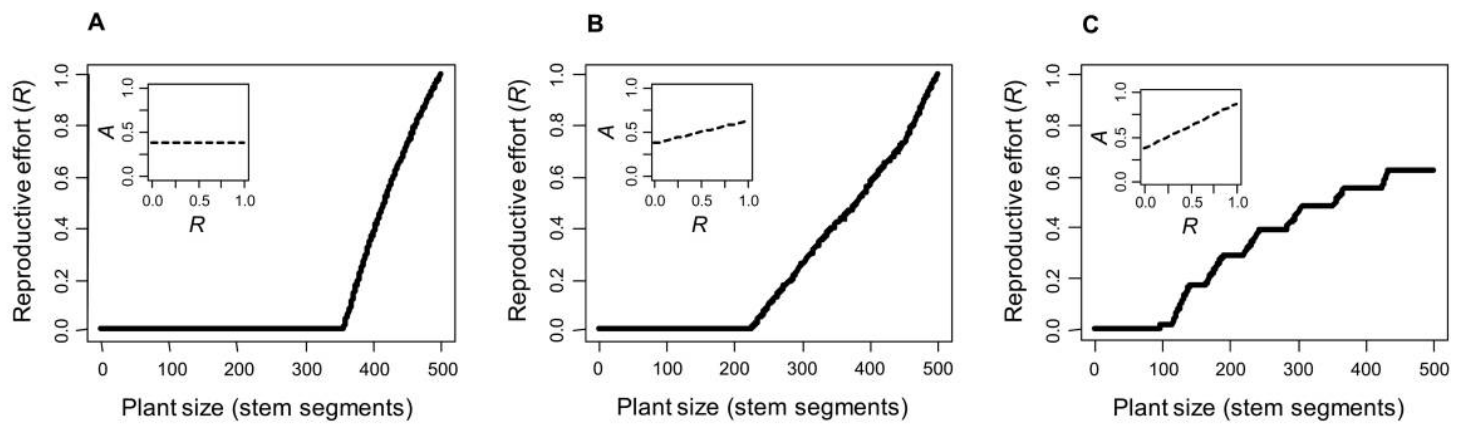

D

E

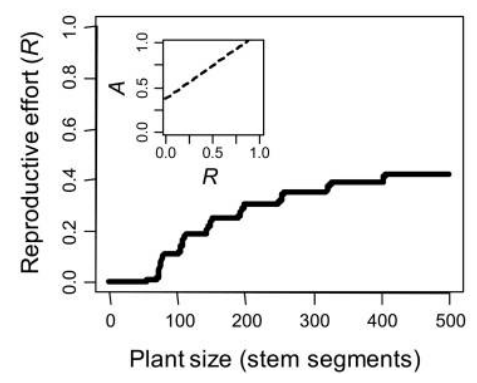

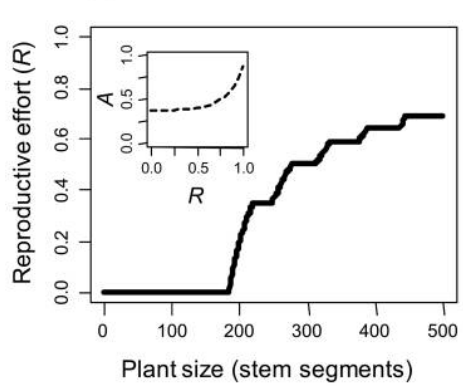

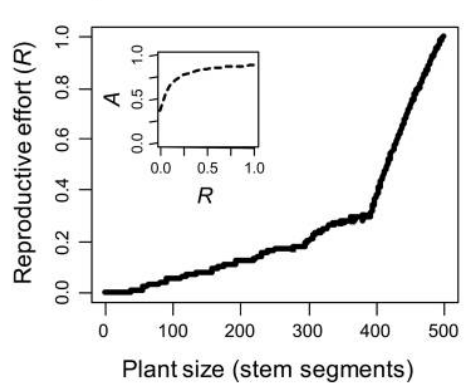

Figure 3: Optimal size-dependent reproductive effort $(R)$ predicted by a state dynamic programming (SDP) model. All model predictions include direct costs of reproduction, but $A-F$ vary in the strength of ecological costs according to the functions shown in the upper left of each panel; these functions describe the relationship between herbivore-induced floral abortion $(A)$ and reproductive effort $(R)$. $A$, Direct costs of reproduction only. $B$, Direct + weak ecological costs ( $50 \%$ weaker slope of $A-R$ relationship than empirical estimate). $C$, Direct + ecological costs (empirical estimate from tree cholla-cactus bug interaction). $D$, Direct + strong ecological costs (50\% greater slope of $A-R$ relationship than empirical estimate). $E, F$, Direct + nonlinear (concave and convex, respectively) ecological costs of reproduction. 


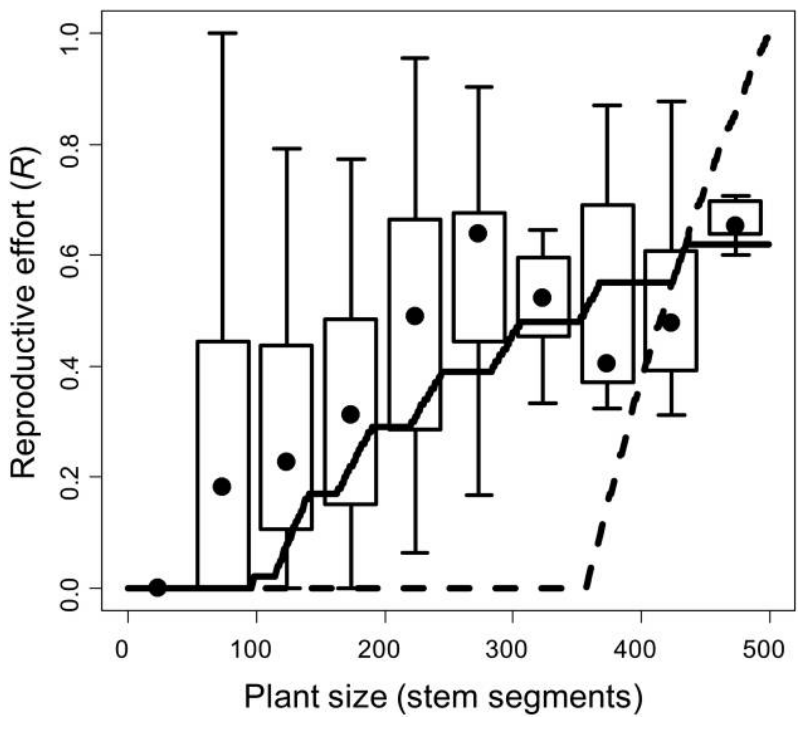

Figure 4: Comparison of optimal versus observed reproductive effort $(R)$ by tree cholla cacti in relation to plant size. Lines show optimality predictions based on direct costs only (dashed line; as in fig. $3 A$ ) or based on direct plus herbivore-mediated ecological costs (solid line; as in fig. $3 C$ ). Box plots show median (dots), interquartile (boxes), and twentyfifth and seventy-fifth percentiles (lower and upper bars, respectively) from independent empirical data on tree cholla reproductive effort.

our estimates of tree cholla-cactus bug interactions. By contrast, the optimality model failed to describe the empirical data when herbivore-mediated costs of reproduction were ignored (fig. 4).

\section{Discussion}

Direct costs of reproduction, resulting from allocation trade-offs between current and future fitness gains, are well studied and are widely thought to play an important role in the evolution of plant life histories (Bazzaz and Grace 1997; Vuorisalo and Mutikainen 1999; Obeso 2002; Reekie and Bazzaz 2005). The goals of this study were to examine the occurrence of additional indirect costs of reproduction, mediated by herbivores, and to evaluate whether and how these costs influence plant life-history strategies. Field experiments indicated that increasing reproductive allocation by tree cholla cacti led to an increase in the frequency of interactions with cactus bugs and that these insects, in turn, reduced flowering success (fig. 2), a major component of fitness. These data provide, to our knowledge, the first experimental evidence for an indirect, herbivore-mediated cost of plant reproduction. In an analogous case study, Roche et al. (1995) found that flowering Silene alba were more likely to become infected with an anther-smut fungus (Ustilago violacea) than were non- flowering plants, as a result of increased activity of pollinators (the fungal vectors), though the consequences for plant reproductive strategies were not considered.

To integrate our empirical results into life-history theory, our theoretical work examined the influence of ecological costs on optimal resource allocation strategies. A dynamic programming model, parameterized with the experimental data, showed that herbivore-mediated costs dramatically influenced the optimal plant reproductive strategy. When only direct costs were considered, plants were predicted to maximize lifetime fitness by allocating meristems exclusively to vegetative growth until reaching a large size and then rapidly increasing $R$ with size. In this case, the gains in fecundity at the largest sizes outweighed the losses of forgoing reproduction at smaller sizes. However, under both direct and ecological costs of reproduction, this strategy was no longer viable because large reproductive events disproportionately attracted flower budfeeding insects. When faced with herbivore-mediated costs of reproduction, plants were expected to maximize lifetime fitness by initiating reproductive allocation at a much smaller size and avoiding large reproductive events. Our sensitivity analysis (fig. 3) showed that as ecological costs increased in severity, fitness was maximized by an increasingly even distribution of $R$ across the plant size trajectory, reflecting diminishing returns on high reproductive investment. Interestingly, when $A$ was constant (direct costs only), increasing its value had no effect on model predictions (not shown). Thus, fitness impacts of herbivores, alone, were not sufficient to alter the optimal allocation strategy. Rather, these impacts must be coupled with a dynamic response by herbivores to plant allocation.

The reproductive "behavior" of tree cholla in the field clearly showed the signature of ecological costs of reproduction (fig. 4). In contrast, the independent empirical data were poorly described by the optimality model when only direct costs were considered. Thus, accounting for constraints on reproductive allocation imposed by herbivores was necessary to explain the tree cholla life history. These results provide strong support for the hypothesis that ecological costs of reproduction imposed by flower bud-feeding herbivores have contributed, over evolutionary time, to the contemporary pattern of size-dependent reproductive effort in this species. This interpretation, as opposed to a plastic response to current or recent herbivore pressure, is supported by experimental data showing no within-generation effects of insect exclusion on tree cholla reproductive effort (see fig. A3 in the online edition of the American Naturalist).

The ecological costs model tended to underpredict reproductive effort, particularly for small plants (fig. 4), and at least two factors may help explain this result. First, the fitness surface associated with direct + ecological costs 
showed that small deviations from the optimal $R$, at a given size, would result in only slight reductions in lifetime fitness (fig. A2). In addition, the rather diffuse relationship between tree cholla reproductive effort and cactus bug abundance ( $R$ explained $\sim 7 \%$ of the variation in bug counts) could further widen the range of viable allocation strategies. Thus, our analysis suggests that the allocation pattern of plants in the field, while not perfectly optimal at all points in the size distribution, would still confer relatively high fitness. Second, the SDP model assumes that all parameter values are constant across a plant's lifetime. Theory predicts that temporal fluctuations in the environment favor the evolution of "cautious" life histories, where reproduction occurs more frequently and at smaller sizes than expected in a constant environment (Cole 1954; Charlesworth 1994). Accordingly, stochasticity may contribute to the observed greater-than-expected reproductive effort by small plants.

The model assumption of temporal constancy also raises the possibility that stochasticity, rather than ecological costs of reproduction, may account for the mismatch between the empirical data and the predicted life history based on direct costs only (fig. 4). Notably, there was significant variation in rates of floral abortion among the 4 years of the field experiment (fig. 2B). However, in our ongoing studies, we have found that including stochasticity in floral abortion or in the impacts of herbivory on floral abortion does not alter the predictions of the SDP model. Rather, stochasticity changes optimal strategies only when it affects the plant's state (T. E. X. Miller and B. Tenhumberg, unpublished data). Because tree cholla growth increments are far less variable across years than reproductive success (T. E. X. Miller, unpublished data), we think that stochasticity, alone, is an unlikely alternative explanation for the life-history patterns we observed in the field.

In conclusion, this study demonstrates that the biotic environments in which plant life histories evolve are more dynamic than previously recognized. Antagonists can respond to plant allocation decisions, resulting in distinctly different reproductive strategies than would be expected based solely on direct costs of reproduction. Our results were driven by two key features of the tree cholla-cactus bug system. First, herbivory increased with plant reproductive effort, and second, herbivores had negative effects on an important component of plant fitness. Both of these features appear common in plant-insect interactions; examples of a positive relationship between plant reproduction and susceptibility to herbivores (particularly those that specialize on reproductive structures) are accumulating in the literature (e.g., Ayal and Izhaki 1993; Johnson and Agrawal 2005; Miller et al. 2006), and the impacts of herbivores on plant fitness and reproductive success are well established (e.g., Doak 1992; Louda and Potvin 1995;
Maron 1998; Ehrlen 2003). On the basis of the strength of our findings and the potential ubiquity of the driving mechanisms, we advocate that plant life-history theory should explicitly account for both direct and indirect ecological costs as selective forces in the evolution of reproductive strategies.

\section{Acknowledgments}

The faculty and staff of the Sevilleta long-term ecological research (LTER) site and Sevilleta National Wildlife Refuge provided valuable logistical support. We thank D. Doak, E. Gering, I. Loladze, and two anonymous reviewers for helpful comments on this work. This research was funded by grants to T.E.X.M. from the Sevilleta LTER (National Science Foundation grant DEB-0217774) and from the Initiative for Ecological and Evolutionary Analysis at the University of Nebraska-Lincoln. T.E.X.M. was supported by a graduate training fellowship from the U.S. Department of Education (Graduate Assistance in Areas of National Need).

\section{Literature Cited}

Agrawal, A. A., P. M. Gorski, and D. W. Tallamy. 1999. Polymorphism in plant defense against herbivory: constitutive and induced resistance in Cucumis sativus. Journal of Chemical Ecology 25:22852304.

Agrawal, A. A., A. Janssen, J. Bruin, M. A. Posthumus, and M. W. Sabelis. 2002. An ecological cost of plant defence: attractiveness of bitter cucumber plants to natural enemies of herbivores. Ecology Letters 5:377-385.

Ayal, Y., and I. Izhaki. 1993. The effect of the mirid bug Capsodes infuscatus on fruit production of the geophyte Asphodelus ramosus in a desert habitat. Oecologia (Berlin) 93:518-523.

Bazzaz, F., and J. Grace. 1997. Plant resource allocation. Academic Press, San Diego, CA.

Benson, L. 1982. Cacti of the United States and Canada. Stanford University Press, Stanford, CA.

Calow, P. 1979. The cost of reproduction: a physiological approach. Biological Reviews of the Cambridge Philosophical Society 54:3240.

Charlesworth, B. 1994. Evolution in age-structured populations. Cambridge University Press, New York.

Clark, C. W., and M. Mangel. 2000. Dynamic state variable models in ecology: methods and applications. Oxford University Press, Oxford.

Cole, L. C. 1954. The population consequences of life history phenomena. Quarterly Review of Biology 29:103-137.

Courtney, S. P. 1985. Apparency in coevolving relationships. Oikos 44:91-98.

Da Costa, C. P., and C. M. Jones. 1971. Cucumber beetle resistance and mite susceptibility controlled by the bitter gene in Cucumis sativus L. Science 172:1145-1146.

Doak, D. F. 1992. Lifetime impacts of herbivory for a perennial plant. Ecology 73:2086-2099.

Ehrlen, J. 2003. Fitness components versus total demographic effects: 
evaluating herbivore impacts on a perennial herb. American Naturalist 162:796-810.

Ehrlen, J., and J. van Groenendael. 2001. Storage and the delayed costs of reproduction in the understorey perennial Lathyrus vernus. Journal of Ecology 89:237-246.

Harper, J. L. 1977. The population biology of plants. Academic Press, New York.

Johnson, M. T., and A. A. Agrawal. 2005. Plant genotype and environment interact to shape a diverse arthropod community on evening primrose (Oenethera biennis). Ecology 86:874-885.

Klinkhamer, P. G. L., T. Kubo, and Y. Iwasa. 1997. Herbivores and the evolution of the semelparous perennial life-history of plants. Journal of Evolutionary Biology 10:529-550.

Louda, S. M., and M. A. Potvin. 1995. Effect of inflorescence-feeding insects in the demography and lifetime fitness of a native plant. Ecology 76:229-245.

Mann, J. 1969. Cactus-feeding insects and mites. Smithsonian Institution, Washington, DC.

Maron, J. L. 1998. Insect herbivory above- and belowground: individual and joint effects on plant fitness. Ecology 79:1281-1293.

McFarland, J. D., P. G. Kevan, and M. A. Lane. 1989. Pollination biology of Opuntia imbricata (Cactaceae) in southern Colorado. Canadian Journal of Botany 67:24-28.

Miller, T. E. X. 2007a. Demographic models reveal the shape of density dependence for a specialist herbivore on variable host plants. Journal of Animal Ecology 76:722-729.

. 2007b. Does having multiple partners weaken the benefits of facultative mutualism? a test with cacti and cactus-tending ants. Oikos 116:500-512.

- $2007 c$. Interactions between cacti and cactus-feeding insects: causes and consequences of variation. $\mathrm{PhD}$ diss. University of $\mathrm{Ne}-$ braska, Lincoln.

Miller, T. E. X., A. J. Tyre, and S. M. Louda. 2006. Plant reproductive allocation predicts herbivore dynamics across spatial and temporal scales. American Naturalist 168:608-616.

Ness, J. H. 2006. A mutualism's indirect costs: the most aggressive plant bodyguards also deter pollinators. Oikos 113:506-514.

Obeso, J. R. 2002. The costs of reproduction in plants. New Phytologist 155:321-348.

Partridge, L., and P. H. Harvey. 1988. The ecological context of life history evolution. Science 241:1449-1455.

Partridge, L., R. Sibly, R. J. H. Beverton, and W. G. Hill. 1991. Constraints in the evolution of life histories: discussion. Philo- sophical Transactions of the Royal Society B: Biological Sciences 332:3-13.

Pimienta-Barrios, E., and R. F. del Castillo. 2002. Reproductive biology. Pages 75-90 in P. S. Nobel, ed. Cacti: biology and uses. University of California Press, Berkeley.

Primack, R., and E. Stacey. 1998. Cost of reproduction in the pink lady's slipper orchid (Cypripedium aucale, Orchidaceae): an elevenyear experimental study of three populations. American Journal of Botany 85:1672-1679.

Prins, A. H., H. W. Nell, and P. G. L. Klinkhamer. 1992. Sizedependent root herbivory on Cynoglossum officinale. Oikos 65:409413.

Reekie, E. G., and F. A. Bazzaz. 2005. Reproductive allocation in plants. Elsevier, Amsterdam.

Roche, B. M., H. M. Alexander, and A. D. Maltby. 1995. Dispersal and disease gradients of anther-smut infection of Silene alba at different life stages. Ecology 76:1863-1871.

Roff, D. A. 2002. Life history evolution. Sinauer, Sunderland, MA.

Rose, K. E., S. M. Louda, and M. Rees. 2005. Demographic and evolutionary impacts of native and invasive insect herbivores: a case study with Platte thistle, Cirsium canescens. Ecology 86:453465 .

Stearns, S. C. 1992. The evolution of life histories. Oxford University Press, Oxford.

Strauss, S. Y., D. H. Siemens, M. B. Decher, and T. Mitchell-Olds. 1999. Ecological costs of plant resistance to herbivores in the currency of pollination. Evolution 53:1105-1113.

Strauss, S. Y., J. A. Rudgers, J. A. Lau, and R. E. Irwin. 2002. Direct and ecological costs of resistance to herbivory. Trends in Ecology \& Evolution 17:278-285.

Tenhumberg, B., M. A. Keller, H. P. Possingham, and A. J. Tyre. 2001. The effect of resource aggregation at different scales: optimal foraging behavior of Cotesia rubecula. American Naturalist 158:505518 .

Tenhumberg, B., G. Siekman, and M. A. Keller. 2006. Optimal time allocation in parasitic wasps searching for hosts and food. Oikos 113:121-131.

Tuttle, M. D., and M. J. Ryan. 1981. Bat predation and the evolution of frog vocalizations in the Neotropics. Science 214:677-678.

Vuorisalo, T., and P. Mutikainen. 1999. Life history evolution in plants. Kluwer, Dordrecht.

Associate Editor: Marc Mangel Editor: Monica A. Geber 